\title{
Validation of Spectrophotometric Method for Determination of Oseltamivir in Pharmaceutical Formulation Using 7-Chloro- 4-Nitrobenzo-2-Oxa-1, 3-Diazole
}

\author{
Afraa Ali Abdel-aziz Hassan and Abdalla Ahmed Elbashir ${ }^{*}$ \\ Faculty of Science, Department of Chemistry, University of Khartoum, Sudan
}

\begin{abstract}
A sensitive, precise and simple spectrophotometric method has been proposed and validated for the determination of oseltamivir (OSL) in pharmaceutical formulations. The proposed method is based on the reaction between the OSL and 7-chloro-4-nitrobenzo-2-oxa-1,3-diazole (NBD-CL) at alkaline medium $(\mathrm{pH} 10)$ to form deep brown adduct, exhibiting maximum absorption $\left(\lambda_{\max }\right)$ at $464 \mathrm{~nm}$. Under optimized reaction condition, the method was linear in the concentration range 2-10 $\mu \mathrm{g} \mathrm{mL}$. The limit of detection (LOD) and limit of quantification (LOQ) were found to be $0.84 \mu \mathrm{g} \mathrm{mL}$,, $2.66 \mu \mathrm{g}$ $\mathrm{mL}^{-1}$, respectively. The method was applied successfully to the determination of OSL in pharmaceutical formulation. A proposal of the reaction pathway has been postulated. The method is useful for routine analysis of OSL in quality control laboratories.
\end{abstract}

\section{Keywords}

Oseltamivir, Spectrophotometric, Pharmaceutical formulation, Method validation, NBD-CL

\section{Abbrevations}

OSL: Oseltamivir phosphate; OC: Oseltamivir carboxylate; LOD: Limit of detection; LOQ: Limit of quantification; SD: Standard deviation

\section{Introduction}

Oseltamivir phosphate (OSL) is the first orally available inhibitor of influenza virus neuraminidase, an enzyme involved in the release of new virus particles from infected cells. The structure of OSL indicates that it possesses a hydrophobic moiety. OSL hydrophobic group is responsible for its poor oral absorption; thus, the phosphate salt has been developed that allows oral administration of this drug. OSL phosphate is a pro drug that is rapidly and extensively metabolized via hepatic esterases to oseltamivir carboxylate (OC), the active form, a potent and selective inhibitor of influenza virus neuraminidase [1-4]. It was developed by Gilead Sciences and is currently marketed by Hoffmann-La Roche (Roche) under the trade name Tamiflu, that is the leading drug against avian flu. The manufacturer has permitted arrangements for a number of companies to produce Tamiflu under License to meet fast-growing world demand for this drug [5]. Tamiflu is already in short supply throughout the world as countries gather stockpiles of the drug among fears of a possible avian flu pandemic $[6,7]$.

Among the various method available for the determination of drugs, spectrophotometry and spectroflourimetry continue to be very popular, because of their simplicity, spec- ificity and low cost. This study presents a new spectrophotometric method for the assay of oseltamivir.

A number analytical procedures have been reported for the analysis of oseltamivir in a bulk form, pharmaceutical form or biological fluids. These include high performance liquid chromatography [8-13], HPTLC [14] spectrophotometric methods [15-17], spectroflourimetry [18] and capillary electrophoresis [19]. However, some of these methods are complicated and time consuming, involve the use of large volume organic solvents and specific reagent and requirement of expensive instruments.

7-Chloro-4-nitrobenzo-2-oxa-1,3-diazole (NBD-CL) has

*Corresponding author: Prof. Abdalla Ahmed Elbashir, Faculty of Science, Department of Chemistry, University of Khartoum, Khartoum, Sudan

Accepted: October 19, 2020

Published online: October 21, 2020

Citation: Hassan AAA, Elbashir AA (2020) Validation of Spectrophotometric Method for Determination of Oseltamivir in Pharmaceutical Formulation Using 7-Chloro-4-Nitrobenzo-2-Oxa-1, 3-Diazole. Current Trends Anal Bioanal Chem 4(1):145-150 
Citation: Hassan AAA, Elbashir AA (2020) Validation of Spectrophotometric Method for Determination of Oseltamivir in Pharmaceutical Formulation Using 7-Chloro-4-Nitrobenzo-2-Oxa-1, 3-Diazole. Current Trends Anal Bioanal Chem 4(1):145-150

been proved to be a useful and sensitive analytical derivatizing agent for spectrophotometric analysis of pharmaceuticals bearing a primary or secondary amino group [20-43]. The applications of NBD-CL for determination of pharmaceutical bearing amine group have been reviewed by Elbashir, et al. $[44,45]$. The use of NBD-CL for spectrophotometric determination of OSL has not been reported yet. Therefore, in this work a sensitive and simple spectrophotometric method for determination of OSL in pharmaceutical formulations has been developed.

\section{Experimental}

\section{Apparatus}

A Shimadzu 1800 UV 1800 spectrophotometer, with $1 \mathrm{~cm}$ quartz cells was used to record the spectrophotometric data. $\mathrm{Mi} 150 \mathrm{pH} /$ Temperature Bench meter was used to adjust $\mathrm{pH}$ of the buffered solutions.

\section{Reagent and solution}

Oseltamivir (OSL) with purity $98.5 \%$ was kindly provided by Hoffman-La Roche. (Foster city, California, USA). Tamiflu $75 \mathrm{mg}$ per capsules was obtained from local pharmacy. 4-Chloro-7-nitrobenzofurazan (NBD-CL) with purity $98 \%$ was obtained from Sigma-Aldrich (Chemie GmbH (Steinheim, Germany). NBD-CL solution was freshly prepared in acetone at $0.7 \%(\mathrm{w} / \mathrm{v})$ concentration. Buffer solution was prepared by adding $12.5 \mathrm{~mL}$ of $0.2 \mathrm{~mol} \mathrm{~L}^{-1} \mathrm{NaOH}$ to $5 \mathrm{~mL} 0.2 \mathrm{~mol} \mathrm{~L}^{-1}$ dihydrogen sodium phosphate. All chemicals and reagent were of analytical-reagent grade. A stock solution of OSL was prepared in distilled water and diluted further with the water to obtain standard solution of $10 \mu \mathrm{g} \mathrm{mL} \mathrm{L}^{-1}$.

\section{Procedure}

Calibration curve: An aliquot of $1.0 \mathrm{~mL}$ from standard solution was added to $2.0 \mathrm{~mL}$ buffer solution in $10 \mathrm{~mL}$ volumetric flask, $0.3 \mathrm{~mL}$ of $0.7 \% \mathrm{NBD}-\mathrm{CL}$ was added to the later and the volume was brought to $10 \mathrm{~mL}$ with water and mixed. The absorbance of the derivative was measured after heating in water bath for $25 \mathrm{~min}$ at $464 \mathrm{~nm}$ against a blank prepared similarly.

Determination of OSL in dosage Forms: For preparation of sample solution, ten capsules were weighed and powdered then a quantity of powder equivalent to $100 \mathrm{mg}$ of OSL was transferred into $100 \mathrm{~mL}$ conical flask, about $70 \mathrm{~mL}$ of water was added, and the mixture was shaken for $10 \mathrm{~min}$ and the volume was made up with water to give a concentration of $1000 \mu \mathrm{g} / \mathrm{mL}$, and then the solution was filtered.

\section{Results and Discussion}

\section{Absorption spectra}

The absorption spectrum of OSL was scanned in range from $185 \mathrm{~nm}$ to $600 \mathrm{~nm}$ against water (Figure 1), it was found that OSL exhibits a maximum absorption peak $\left(\lambda_{\max }\right)$ at 190 $\mathrm{nm}$. Because of highly blue shifted $\lambda_{\max }$ of OSL, its determination in the dosage form based on the direct measurement of its absorption for ultraviolet is susceptible to potential interferences from the common excipients. Therefore, deri-

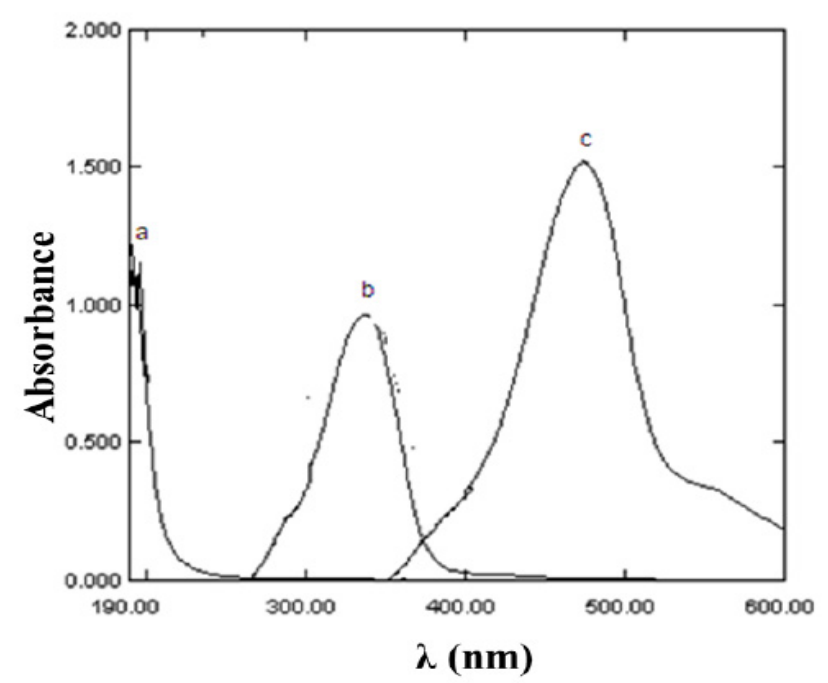

Figure 1: Absorption spectrum of OSL (a) NBD-CL; (b) Reaction product of OSL with NBD-CL; (c) Against reagent blank.

Conditions: OSL $\left(5 \mu \mathrm{g} \mathrm{ml}^{-1}\right)$, NBD-CL $(0.7 \%, \mathrm{w} / \mathrm{v})$ and $\mathrm{pH} 10.0$.

vatization of OSL red-shifted light-absorbing derivative was necessary. The reaction between OSL and NBD-CL was performed, and the absorption spectrum of the product was recorded against reagent blank (Figure 1). It was found that the product is brown colored exhibiting $\lambda_{\text {max }}$ at $464 \mathrm{~nm}$, and the $\lambda_{\max }$ of NBD-CL was $342 \mathrm{~nm}$. The $\lambda_{\max }$ of OSL-NBD-CL derivative was red-shifted, eliminating any potential interference. Therefore, the measurements were carried out at $464 \mathrm{~nm}$.

\section{Optimization of reaction conditions}

The optimum conditions for the development of method were established by varying the parameters one at a time while keeping the others fixed and observing the effect produced on the absorbance of the colored product. In order to establish experimental conditions, the effect of various parameters such as, $\mathrm{pH}$, concentration of NBD-CL temperature, and time of heating were studied. Observing the effect produced on the absorbance of the colored product. In order to establish experimental conditions, the effect of various parameters such as, $\mathrm{pH}$ concentration of NBD-CL temperature, and time of heating were studied.

The influence of $\mathrm{pH}$ on the absorbance of product was investigated in the range of 7.0-12.0, the absorbance of the solution increases rapidly up to $\mathrm{pH} 10$ and then decrease (Figure 2). At pH 10.0, the absorbance reaches its maximum; in other words, the degree of the nucleophilic substitution reaction is also maximal. At $\mathrm{pH}>10.0$, the absorbance of solution decreases sharply. Presumably it may be that the increase of hydroxide ion holds back the nucleophilic substitution reaction between OSL and the chromogenic reagent. Consequently, the absorbance of the solution reduces. In order to keep the high sensitivity for the determination of OSL, pH 10.0 was selected for optimal experimental conditions.

The effect of NBD-CL concentration was studied over the range $0.4-0.8 \%(w / v)$ as shown in (Figure 3$)$. Increasing the concentration of NBD-CL results in more products up to an 


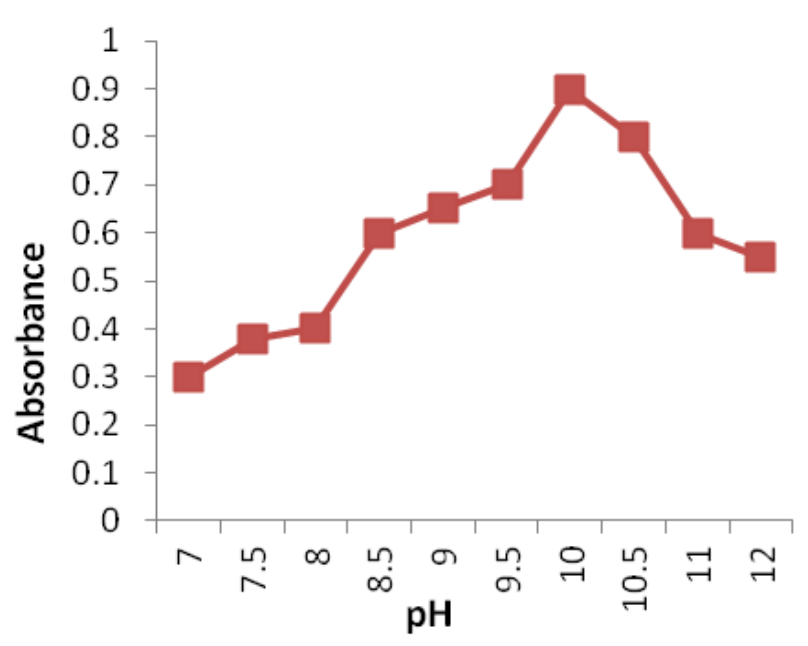

Figure 2: The Effect of $\mathrm{pH}$ on the reaction of the reaction product of OSL - NBD-CL $=$ OSL $\left(5 \mu \mathrm{g} / \mathrm{ml}^{-1}\right)+0.3 \mathrm{ml} \mathrm{NBD}-\mathrm{CL} 0.7 \%$ for 25 $\min$ at $50{ }^{\circ} \mathrm{C}$.

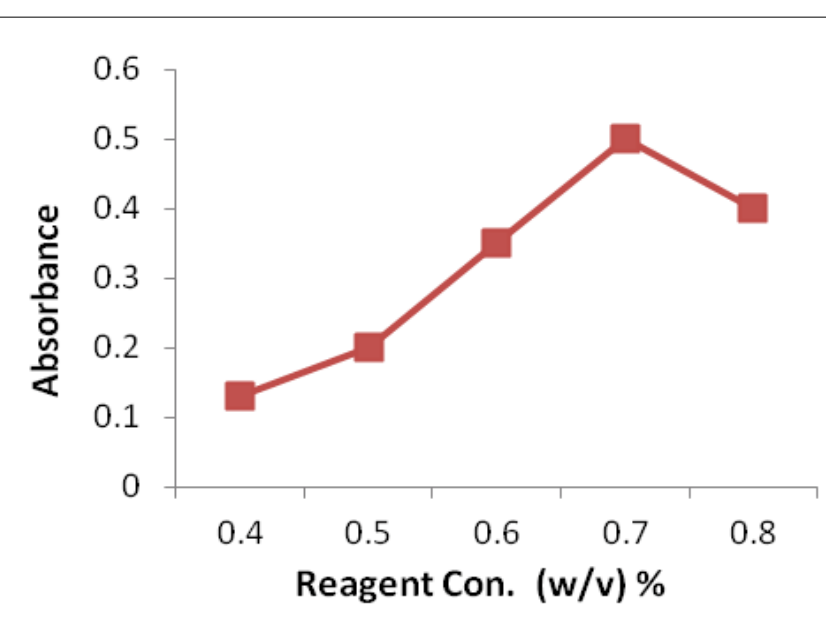

Figure 3: Effect of NBD-CL concentration on the reaction of the reaction product of OSL - NBD-CL $=$ OSL $\left(5 \mu \mathrm{g} / \mathrm{ml}^{-1}\right)+0.3 \mathrm{ml} \mathrm{NBD}$ $\mathrm{CL} 0.7 \%$ for $25 \mathrm{~min}$ at $50{ }^{\circ} \mathrm{C}$.

amount of $0.7 \%$, after which the absorbance of the solution reduced. Therefore, a concentration of $0.7 \%$ NBD-CL was considered optimum. Keeping $\mathrm{pH}$ at 10.0, the effect of amount of buffer solution on the absorbance of product was also studied. It shows that the absorbance of product enhances rapidly with the rise of amount of buffer solution, and becomes maximal when the amount of buffer solution is $2.0 \mathrm{~mL}$. Therefore, the amount of $2.0 \mathrm{~mL}$ buffer solution was selected to ensure the highest absorbance of product, as shown in (Figure 4).

The effect of temperature on the reaction was studied by carrying out the reaction at different temperatures (30-70 $\left.{ }^{\circ} \mathrm{C}\right)$. It was found that the reaction of OSL with NBD-CL was affected by increasing the temperature, and the reaction at 50 ${ }^{\circ} \mathrm{C}$ went to completion in 25 minutes, as shown in (Figure 5) and therefore, further experiments involving NBD-CL reagent were carried out at $50{ }^{\circ} \mathrm{C}$ for 25 minutes.

From the above experiments, the optimized conditions used for the assay were: $\mathrm{pH} 10.0, \mathrm{NBD}-\mathrm{CL}$ concentration $0.7 \%$ $\mathrm{w} / \mathrm{v}$, volume of the buffer $2.0 \mathrm{~mL}$, reaction time $25 \mathrm{~min}$ and temperature $50^{\circ} \mathrm{C}$.

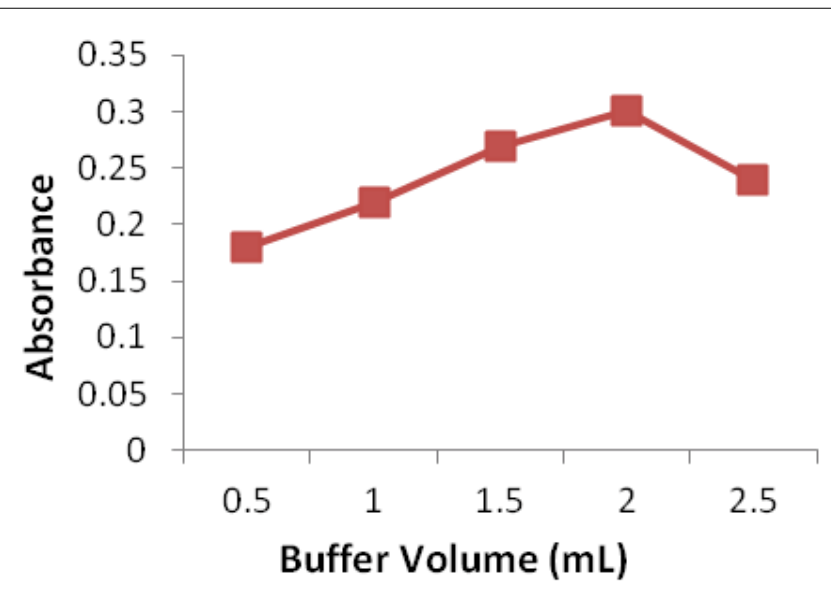

Figure 4: Effect of the volume of the buffer on the reaction of the reaction product of OSL - NBD-CL $=$ OSL $\left(5 \mu \mathrm{g} / \mathrm{ml}^{-1}\right)+0.3 \mathrm{ml}$ NBD-CL $0.7 \%$ for $25 \mathrm{~min}$ at $50^{\circ} \mathrm{C}$.

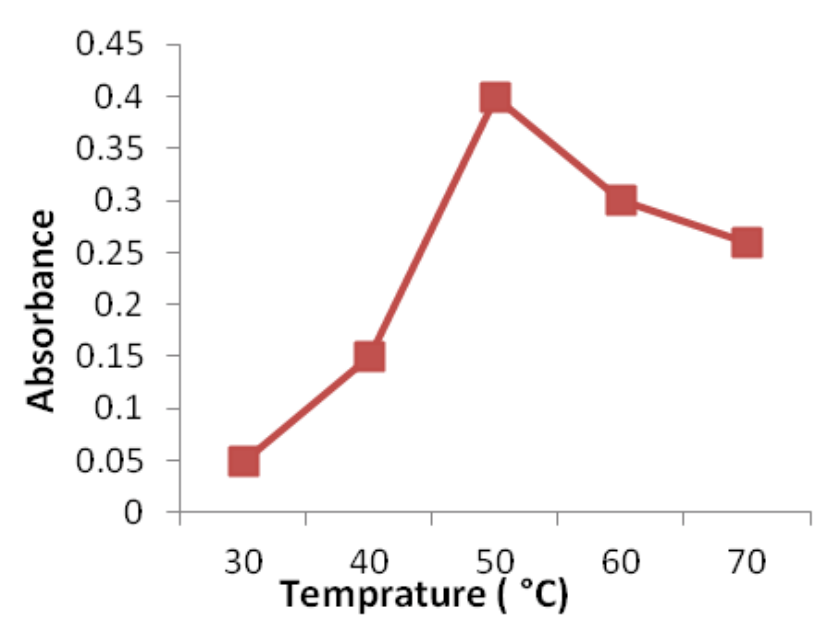

Figure 5: Effect of the temperature on the reaction of the reaction product of OSL - NBD-CL $=$ OSL $\left(5 \mu \mathrm{g} / \mathrm{ml}^{-1}\right)+0.3 \mathrm{ml} \mathrm{NBD-}$ $\mathrm{CL} 0.7 \%$ for $25 \mathrm{~min}$ at $50^{\circ} \mathrm{C}$.

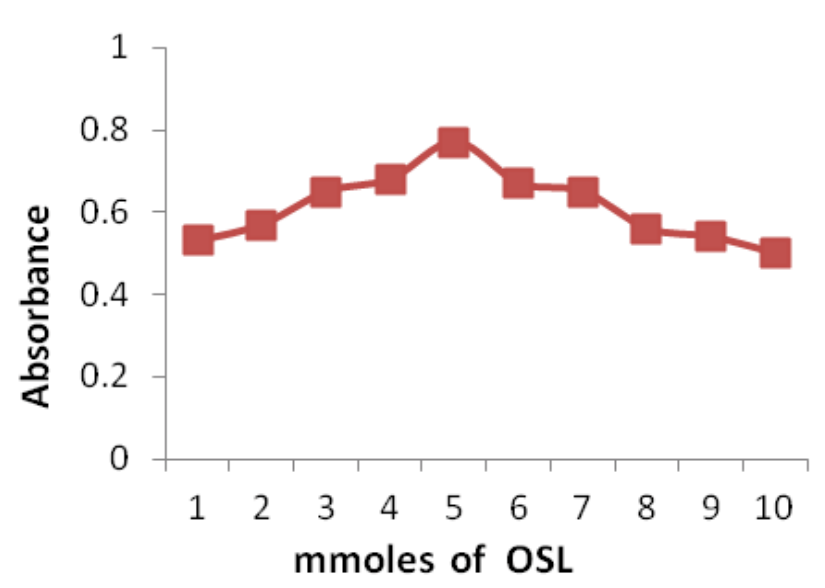

Figure 6: The continuous variation plot for the stoichiometry of the reaction of OSL with NBD-CL.

Furthermore, the molar ratio of NBD-CL to OSL in the reaction mixture was studied according to Job's method of continuous variation [46]. A $5.0 \times 10^{-4} \mathrm{~mol} \mathrm{~L}^{-1}$ standard solution 
Citation: Hassan AAA, Elbashir AA (2020) Validation of Spectrophotometric Method for Determination of Oseltamivir in Pharmaceutical Formulation Using 7-Chloro-4-Nitrobenzo-2-Oxa-1, 3-Diazole. Current Trends Anal Bioanal Chem 4(1):145-150

of OSL and solution of NBD-CL were used. The reaction stoichiometry was found to be a good approximation 1:1 ratio (drug/reagent), confirming that one molecule of OSL reacts with one molecule of NBD-CL (Figure 6). Based on the observation molar ratio, the reaction pathway was postulated to proceed as shown in (Scheme 1).

\section{Analytical method validation}

Under the described experimental conditions, linear rela-

Table 1: Parameter for the performance of the proposed method.

\begin{tabular}{|l|l|}
\hline Parameter & value \\
\hline Measurement wavelength & $464 \mathrm{~nm}$ \\
\hline Linear range & $2-10 \mu \mathrm{gL}^{-1}$ \\
\hline Regression equation & $\mathrm{Y}=0.00125 \mathrm{X}+0.289$ \\
\hline Slope \pm SD & $0.00125 \pm 0.00005$ \\
\hline Intercept \pm SD & $0.289 \pm 0.000332$ \\
\hline Correlation coefficient ( $\left.{ }^{2}\right)$ & 0.997 \\
\hline Limit of Detection (LOD ) & $0.8448 \mu \mathrm{g} \mathrm{ml}^{-1}$ \\
\hline Limit of Quantification (LOQ) & $2.656 \mu \mathrm{ml}^{-1}$ \\
\hline Molar absorptivity (L mol-1 $\left.\mathrm{cm}^{-1}\right)$ & $4.64 \times 10^{3}$ \\
\hline
\end{tabular}

tionship was found between the absorbance at $\lambda_{\max } 464 \mathrm{~nm}$ and the concentration of the drug. The regression equation was found to be as $Y=0.00125 X+0.289\left(r^{2}=0.997, n=7\right)$ (where $A$ is the absorption, and $c$ is the concentration of OSL in $\mu \mathrm{g} \mathrm{mL}^{-1}$ ) the limits of detection (LOD) and limits of quantitation (LOQ) where determined using the formula:

LOD or LOQ $=$ K S D. $a / b(1)$

Where,

$K=3.3$ for LOD and 10 for LOQ, S. D. $a$ is the standard deviation of the intercept, and $b$ is the slope, the obtained results are summarized on (Table 1 ).

The accuracy of the proposed method was carried out by applying standard addition technique. A different amount of standard solution was added to a known concentration of the drug sample. The average percent recoveries obtained in range 99.25-100.75 (Table 2).

Robustness was examined by evaluating the influence of small variation in the method variables on its analytical performance. In these experiments, one parameter was changed whereas the others were kept unchanged, and the recovery percentage was calculated each time. It was found that variation in the NBD-CL concentration of $0.7 \pm 0.02 \%(w / v)$ and

Table 2: Recovery studies for the determination of OSL by proposed method.

\begin{tabular}{|l|l|l|l|l|}
\hline Sample No & Sample content $\left(\boldsymbol{\mu g} \mathbf{~ m L}^{-1}\right)$ & OSL amount added & Amount Found \\
\hline 1 & 4 & 3.5 & 7.53 & $100.75 \%$ \\
\hline 2 & 4 & 7.0 & 10.90 & $97.5 \%$ \\
\hline 3 & 4 & 12.0 & 15.97 & $99.25 \%$ \\
\hline
\end{tabular}<smiles>CCOC(=O)C1=CC(OC(CC)CC)C(NC(C)=O)C(N)C1</smiles>

Scheme 1: Reaction pathway of OSL with NBD-Cl. 
Citation: Hassan AAA, Elbashir AA (2020) Validation of Spectrophotometric Method for Determination of Oseltamivir in Pharmaceutical Formulation Using 7-Chloro-4-Nitrobenzo-2-Oxa-1, 3-Diazole. Current Trends Anal Bioanal Chem 4(1):145-150

Table 3: Results of robustness for determination of OSL by the proposed method.

\begin{tabular}{|l|l|l|}
\hline \multirow{2}{*}{ NBD-CL concentration } & Parameter & \multicolumn{1}{c|}{ Recovery (\%) } \\
\cline { 2 - 3 } & Recommended conditions & 101.36 \\
\hline Buffer pH & NBD-CL concentration (\%0.68) & 99.00 \\
\hline & NBD-CL concentration (\%0.72) & 100.00 \\
\hline Temperature & Buffer $\mathrm{pH} 9.5$ & 98.20 \\
\hline & Buffer $\mathrm{pH} 10.5$ & 99.40 \\
\hline Reaction time & Temperature $\left(4 \mathbf{~}^{\circ} \mathrm{C}\right)$ & 99.80 \\
\hline & Temperature $\left(52^{\circ} \mathrm{C}\right)$ & 98.20 \\
\hline & Reaction time $(\min ) 23$ & 102.22 \\
\hline & Reaction time $(\mathrm{min}) 27$ & 96.60 \\
\hline
\end{tabular}

optimal experimental conditions of temperature $\left(50 \pm 2{ }^{\circ} \mathrm{C}\right)$, time $(25 \pm 2 \mathrm{~min})$ and $\mathrm{pH}(10.0 \pm 0.5)$, did not significantly affect the procedures and recovery values were $96.6-102.2 \%$ and the RSD values did not exceed $0.497 \%$ (Table 3 ).

\section{Conclusion}

In this work, the product of the derivatization reaction between OSL and NBD-Cl has been utilized to develop a simple accurate and sensitive spectrophotometric method for OSL analysis in pharmaceutical formulation. The derivatization reactions conditions were optimized. The suggested mechanism was postulated. The method was validated with respect to linearity, limit of detection (LOD) and limit of quantification (LOQ), accuracy and robustness. The method is also cost effective and environmentally friendly; therefore, the proposed method can be used advantageously as a routine method for the determination of OSL in quality control and industry.

\section{References}

1. Mc Clellan K, Perry CM (2001) Oseltamivir: A review of its use in influenza. Drugs 61: 263-283.

2. Dreitlein WB, Maratos J, Brocavich J (2001) Zanamivir and oseltamivir: Two New options for the treatment and prevention of influenza. Clin Ther 23: 327-355.

3. Hayden FG, Atmar RL, Schilling M, et al. (1999) Use of the selective oral neuraminidase inhibitor oseltamivir to prevent influenza. N Engl J Med 341: 1336-1343.

4. KG Nicholson, FY Aoki, AD Osterhaus, et al. (2000) Efficacy and safety of oseltamivir in treatment of acute influenza: A Randomised controlled trial. Neuraminidase Inhibitor Flu Treatment Investigator Group. Lancet 355: 1845-1850.

5. M Enserink (2006) Oseltamivir becomes plentiful--but still not cheap. Science 312: 382-383.

6. A Abbott, H Pearson (2004) Fear of human pandemic grows as bird flu sweeps through Asia. Nature 427: 472-473.

7. J Oxford (2005) Oseltamivir in the management of influenza. Expert Opinion on Pharmacotherapy 6: 2493-2500.

8. Malipatil SM, Jahan K, Patil SK (2011) Development \& validation of RP-HPLC method for the determination of Oseltamivir phosphatein bulk drug \& in dosage. Indo Global J Pharm Sci 1: 57-62.

9. Narasimhan BM, Abida K, Srinivas K (2008) Stability indicating RP-HPLC method development and validation for Oseltamivir
API. Chem Pharm Bull 56: 413-417.

10. ChabaihH, Ouarezki R, Guermouche S, et al. (2011) Rapid determination of Oseltamivir phosphate in pharmaceutical preparation using monolithic silica HPLC column. J Liq Chromatogr Relat Technol 34: 1913-1924.

11. Lindegardh N, Hien TT, Singhasivanon $P$, et al. (2006) A Simple and rapid liquid chromatographic assay for evaluation of potentially counterfeit Tamiflu. J Pharm Biomed Anal 42: 430-433.

12. Wiltshire H, Wiltshire B, Citron A, et al. (2000) Development of a High-performance liquid chromatographic-mass spectrometric assay for the specific and sensitive quantification of Ro 64-0802, an anti-influenza drug, and its pro-drug, Oseltamivir, in human and animal plasma and urine. J Chromatogr B 745: 373-388.

13. Heinig K, Buchelia F (2008) Sensitive determination of oseltamivir and oseltamivir carboxylate in plasma, urine, cerebrospinal fluid and brain by liquid chromatography-tandem mass spectrometry. J Chromatogr B 876: 129-136.

14. Youssef RM, Khamis EF, Younis SE, et al. (2013) Validated HPTLC method for the evaluation of Oseltamivir pharmaceutical formulations counterfeited with ascorbic acid compared with a colorimetric method. J Planar Chromatogr 5: 427-434.

15. Raut CS, Ghargea DS, Dhabalea PN, et al. (2010) Development and validation of Oseltamivir phosphate in fluvir ${ }^{\circledR}$ by UV-spectrophotometer. J Pharm Technol Res 2: 363-366.

16. Kumar VK, Raju NA (2009) Spectrophotometric estimation of Osel-tamivir in pharmaceutical formulations. Asian J Chem 21: 5984-5988.

17. Green MD, Netty H, Wirtz RA (2008) Determination of Oseltamivir quality by colorimetric and liquid chromatographic methods. Emerg Inf Dis 14: 552-556.

18. Aydogmus $Z$ (2009) Simple and sensitive spectrofluorimetric method for the determination of Oseltamivir phosphate in capsules through derivatization with fluorescamine. J Fluoresc 19: 673-679.

19. Laborde-Kummera E, Guadina K, Joseph-Charlesa J, et al. (2009) Development and validation of a rapid capillary electrophoresis method for the determination of Oseltamivir phosphate in Tamiflu and generic versions. J Pharm Biomed Anal 50: 544-546.

20. Taha EA, Salama NN, Fattah L (2005) Spectrofluorimetric and spectrophotometric stability-indicating methods for determination of some oxicams using 7-chloro-4-nitrobenz-2-oxa-1,3-diazole (NBD-CL). Chem Pharm Bull 54: 653-658. 
Citation: Hassan AAA, Elbashir AA (2020) Validation of Spectrophotometric Method for Determination of Oseltamivir in Pharmaceutical Formulation Using 7-Chloro-4-Nitrobenzo-2-Oxa-1, 3-Diazole. Current Trends Anal Bioanal Chem 4(1):145-150

21. Elbashir AA, Krieger S, Schmitz OJ (2014) Simultaneous determination of polyamines and acetylpolyamine in human urine by capillary electrophoresis with fluorescence detection. Electrophoresis 35: 570-576.

22. Ahmed SM, Elbashir AA, Elhassan YM (2016) Application of 2chloro-7-nitrobenzo-2-oxa-1,3-diazol (NBD-CL) for spectrophotometric determination of finasasteride in pharmaceutical formulation. IJARCS 12: 25-33.

23. Abdelrahman ST, Elbashir AA, El-Mukhtar M, et al. (2016) Application of spectrophotometric methods for the of thiamine(VB1) in pharmaceutical formulation using 7-chloro-4- nitrobenzoxadiazole (NBD-Cl). J Anal Pharm Res 2: 00018.

24. Mohamed TO, Elbashir AA (2015) Spectrophotometric method for determination of gabapentin in pharmaceutical formulation by derivatization with 4- chloro-7-nitrobenzo-2-oxa-1,3-diazol (NBD-CL). Int J Drug Dev \& Res 7: 1-4.

25. Basheir BEA, Elbashir AA (2015) Spectrophotometric method for determination of L-dopa in pharmaceutical formulation using 7- chloro-4-nitrbenzoxadiazole (NBD-CL) as a chromogenic reagent. EJPMR 2: 304-316.

26. Alfaki OMA, Elbashir AA (2019) Utilization of 4-Chloro-7-Nittobenzo-2-Oxa-1, 3-Diazol (NBD-CL) as Chromogenic Reagent for Determination of Metformin hydrochloride (MET) in Pharmaceutical Formulation. Asian Journal of Pharmaceutical Research and Development 27: 19-23.

27. El-Enany N, El-Sherbiny D, Belal F (2007) Spectrophotometric, spectrofluorometric and HPLC determination of desloratadine in dosage forms and human plasma. Chem Pharm Bull 55: 16621670.

28. Saleh HM, EL-Henawee MM, Ragab GH, et al. (2007) Utility of NBD-CL for the spectrophotometric determination of some skeletal muscle relaxant and antihistaminic drugs. Spectrochim Acta A Mol Biomol Spectrosc 67: 1284-1289.

29. Shehata MA, El-Sayed GM, Abdel-Fattah LE (2006) Utilization of 4-chloro-7-nitro-2,1,3-benzoxadiazole (NBD-CL) for kinetic spectrophotometric assay of befunolol hydrochloride in its pharmaceutical formulation. J AOAC Int 89: 646-650.

30. Olojo RO, Xia RH, Abramson JJ (2005) Spectrophotometric and fluorometric assay of superoxide ion using 4-chloro-7-nitrobenzo-2-oxa-1,3-diazole. Anal Biochem 339: 338-344.

31. Olgun N, Erturk S, Atmaca S (2002) Spectrofluorimetric and spectrophotometric methods for the determination of vigabatrin in tablets. J Pharm Biomed Anal 29: 1-5.

32. Onal A, Kepekci SE, Oztunc A (2005) Spectrophotometric methods for the determination of antidepressant drug paroxetine hydrochloride in tablets. J AOAC Int 88: 490-495.

33. Elbashir AA, Babikir AA (2013) Development and validation of spectrophotometric method for determination of pencllamine
PA in pharmaceutical formulation using 4-chloro-7-nitrobenzo2-oxa-1,3-diazol (NBD-CL). World Journal Of Analytical Chemistry 1: 18-22.

34. Omer M, Omar M, Thiel A, et al. (2018) High performance liquid chromatographic methods for analysis of taurine in energy drinks after pre-column derivatization. Eurasian J Anal Chem 13: 1-8.

35. Mohamed SMK, Elbashir AA, Aboul-Enein HY (2017) Spectrophotometric method for determination of taurine in energy drinks. Current Pharmaceutical Analysis 13: 11-17.

36. Basheir BEA, Elbashir AA (2015) Spectrophotometric methods for the determination of L-tyrosine in pharmaceutical formulations, Chem Xpress 8: 95-101.

37. Omar MMA, Elbashir A, Schmitz OJ (2017) Capillary electrophoresis method with UV-detection for analysis of free amino acids concentrations in food. Food Chem 214: 300-307.

38. El-Emam AA, Hansen SH, Moustafa MA, et al. (2004) Determination of lisinopril in dosage forms and spiked human plasma through derivatization with 7-chloro-4-nitrobenzo-2-oxa-1,3diazole (NBD-CL) followed by spectrophotometry or HPLC with fluorimetric detection. J Pharm Biomed Anal 34: 35-44.

39. Amin AS, Ragab GH, Saleh H (2002) Colorimetric determination of $\beta$-blockers in pharmaceutical formulations. J Pharm and Biomed Anal 30: 1347-1353.

40. Abdellatef HE (2002) Kinetic spectrophotometric determination of tramadol hydrochloride in pharmaceutical formulation. J Pharm Biomed Anal 29: 835-842.

41. Darwish IA, Amer SM, Abdine HH, et al. (2009) New Spectrophotometric and Fluorimetric Methods for Determination of Fluoxetine in Pharmaceutical Formulations. Int J Anal Chem 257: 1-9.

42. Önal A, Sagirli O (2009) Spectrophotometric and spectrofluorimetric methods for the determination of pregabalin in bulk and pharmaceutical preparation. Spectrochim Acta A Mol Biomol Spectrosc 72: 68-71.

43. El-Shabrawy Y, Belal F, Sharaf El-Din M, et al. (2003) Spectrophotometric determination of fenoterol hydrobromide in pure form and dosage forms. Farmaco 58: 1033-1038.

44. Elbashir AA, Suliman FO, Aboul-Enein HY (2011) The application of 7-chloro-4-nitrobenzoxadiazole (NBD-CL) for the analysis of pharmaceutical-bearing amine group using spectrophotometry and spectrofluorimetry techniques. Appl Spectros Rev 46: 222241.

45. Elbashir AA, Suliman FO, Aboul-Enein HY (2011) The Application of 7-Chloro-4-Nitrobenzoxadiazole and 4-Fluoro-7-Nitro-2,1,3 Benzoxadiazole for The Analysis of Amines and Amino Acids Using High-Performance Liquid Chromatography. GU J Sci 24: 679697.

46. Job P (1928) Advanced Physiochemical Experiments, (2 ${ }^{\text {nd }}$ edn), Oliner and Boyd, Edinburgh, 1963, Anal Chem 9: 113.

DOI: $10.36959 / 525 / 433$

Copyright: () 2020 Hassan AAA, et al. This is an open-access article distributed under the terms of the Creative Commons Attribution License, which permits unrestricted use, distribution, and reproduction in any medium, provided the original author and source are credited. 